\title{
Assessment of Genetic Diversity for Polygenic Traits in Pigeonpea [Cajanus cajan (L.) Millspaugh]
}

\author{
Syed Mohd Qutadah*, Suhel Mehandi, I.P. Singh and Farindra Singh \\ ICAR-Indian Institute of Pulses Research, Kanpur-208024 (U.P.), India \\ *Corresponding author
}

\begin{tabular}{|l|}
\hline Key w o r d s \\
Pigeonpea, Genetic \\
$\begin{array}{l}\text { Diversity, } \\
\text { Clustering pattern } \\
\text { and Polygenic } \\
\text { traits }\end{array}$ \\
\hline Article Info \\
\hline $\begin{array}{l}\text { Accepted: } \\
\text { 12 December } 2018 \\
\text { Available Online: } \\
\text { 10 January } 2019\end{array}$ \\
\hline
\end{tabular}

\begin{abstract}
The nature and extent of genetic diversity were assessed among 57 pigeonpea accessions comprising release varieties, farmer varieties and reference varieties. All the accessions were grouped into eight different non-overlapping clusters. Among them cluster I, having 17 accessions, emerged with highest number of entries followed by cluster V with 9 accessions, cluster III with 7 accessions, cluster IV with 6 accessions, cluster VI, VII and VIII constituted by 5 accessions each while cluster II, comprised 3 accessions, had least number of entries. The highest contribution in manifestation of genetic divergence was exhibited by 100 -seed weight followed by days to maturity, plant height and days to $50 \%$ flowering. The hybridization between entries belonging to cluster pairs having large intercluster distance and possessing high cluster means for one or other characters to be improved may be recommended for isolating desirable recombinants in segregating generations. In this context highest inter-cluster distance was recorded between cluster $\mathrm{V}$ and VII followed by cluster IV and VI, IV and VII, III and VII while cluster I and III had lowest inter-cluster distance. The promising accessions identified were Bumba Tumur, BDN-2, Chaita Arhar, BSMR-736, Karanja Tuar, Dehati Arhar Lal and Belianga of cluster III; UPAS- 120, Paras, Manak, Dehati Arhar-2, Pusa-992 and Vamban-1 of cluster IV, Ram Arhar, HJP-7, Agahani, Manika Arhar and HJP-9 of cluster VI and NTH-77, Lal Rahri, Desi Arhar-1, Arhar Manpur Pahadi and Rehhe Arhar of cluster VII for exploitation in hybridization programme for development of superior pigeonpea cultivars.
\end{abstract}

\section{Introduction}

Pigeonpea [Cajanus cajan (L.) Millspaugh] is the second most important pulse crop of India after chickpea. It has been recognized as a good source of vegetarian protein particularly in the developing countries where majority of the people depends on the vegetarian foods. As it is evident that ultimate goal of plant breeding programme is to develop improved accessions which are better than the existing ones which require genetic amelioration through maximum utilization of allelic resources. Synthesis of such accessions would depend upon the sound knowledge and understanding of nature and magnitude of gene actions involved in the inheritance of agronomically important traits selection of suitable parents and breeding methodology. 
The information about the nature and magnitude of genetic diversity existing in the available germplasm of a particular crop is crucial for selection of diverse parents, which upon hybridization may provide a wide spectrum of genetic recombinations for quantitatively inherited traits. Darwin 1859 used the expression of divergence in characters to denote variation in genera, species and varieties. Genetically diverse parents are preferred for use in hybridization programme because hybridization involving divergent parents has been found to provide greater possibility for obtaining desirable segregants in segregating generations. The importance of genetic diversity for selecting parents for recombination breeding in crops including pigeonpea to recover transgressive segregants has also been repeatedly emphasized (Moll et al., 1962 and Pratap et al., 2011). Earlier workers considered distances in place of origin as index of genetic diversity and used it for selection of parents for hybridization programme. However, the genetic diversity of the selected parents has not been always found to be based on factors such as geographic diversity/place of release or ploidy level (Muthy and Arunachalam, 1966; Bhatt, 1970). Hence, characterization of genetic divergence for selection of suitable and diverse accessions should be based on sound statistical procedures, such as Mahalanobis $\mathrm{D}^{2}$ cluster analysis. Keeping in view, an experiment was taken up to study genetic diversity for selecting the diverse parents for hybridization programme aimed at isolating desirable segregants for seed yield and other important characters in pigeonpea.

\section{Materials and Methods}

Fifty seven pigeonpea accessions were evaluated in a randomized block design with three replications at Research Farm of ICARIndian Institute of Pulses Research, Kanpur, India. Out of 57 accessions 12 accessions are released varieties and 45 accessions are eight germplasm lines. The experimental site is located at $26.49^{\circ} \mathrm{N}$ latitude, $80.27^{\circ} \mathrm{E}$ longitudes and an altitude of $152.4 \mathrm{~m}$ above mean sea level. Each accession was raised in single row plots of $4 \mathrm{~m}$ length with intra-row and inter-row spacing of $25 \mathrm{~cm}$ and $75 \mathrm{~cm}$, respectively. The recommended agronomic practices followed to raise good crop stand. The observations were recorded on five randomly selected competitive plants of a accessions for eight characters viz., days to $50 \%$ flowering, days to maturity, number of primary branches per plant, plant height $(\mathrm{cm})$, pods per plant, seeds per pod, 100-seed weight $(\mathrm{g})$, seed yield per plant $(\mathrm{g})$,. The mean data were utilized for analysis of variance to test the significance for each character as per methodology advocated by (Panse and Sukhatme, 1967; Mehandi et al., 2013). Genetic diversity was estimated by (Mahalinobis, 1936) and the grouping of the accessions into different clusters was done by using the procedure of (Rao, 1952).

\section{Results and Discussion}

The Mahalanobis $\mathrm{D}^{2}$ cluster analysis grouped all the 57 pigeonpea accessions of the present investigation into eight distinct nonoverlapping clusters (Table 1 and Fig. 1). Among them cluster I, having 17 accessions, emerged with highest number of entries followed by cluster $\mathrm{V}$ with 9 accessions, cluster III with 7 accessions, cluster IV with 6 accessions, cluster VI, VII and VIII comprised by 5 accessions each while cluster II, comprising 3 accessions, had least number of entries. The discrimination of accessions into discrete clusters suggested presence of high degree of genetic diversity in the material evaluated. Earlier workers have also re-ported substantial genetic divergence in the pigeonpea materials (Sawant et al., 2009; Kumar et al., 2011; Katiya et al., 2004; Gupta et al., 2008). Presence of substantial genetic 
diversity among the accessions screened in the present study indicated that this material may serve as good source for selecting the diverse parents for hybridization programme aimed at isolating desirable segregants for seed yield and other important characters.

Clustering pattern of the pigeonpea accessions revealed that the accessions of heterogeneous origin were frequently present in same cluster, although the accessions originated in same place or geographic region were also found to be grouped together in same cluster, the instances of grouping of accessions of different origin or geographical regions in same cluster were observed in case of all the clusters. This indicated lack of any definite relationship or correlation between genetic diversity and geographic origin of the pigeonpea accessions evaluated in the present study. Therefore, the selection of parental material for hybridization programme simply based on geographic diversity may not be rewarding exercise. The choice of suitable diverse parents based on genetic divergence analysis would be more fruitful than the choice made on the basis of geographical distances. This finding is in conformity with the previous reports advocating lack of parallelism between genetic and geographic diversity in pigeonpea (Katiyar et al., 2004 and Nag et al., 2012).

The estimates of average intra- and intercluster distances for five clusters (Table 2, Fig 2) revealed that the accessions present in a cluster have little genetic divergence from each other with respect to aggregate effect of characters under study, while much more genetic diversity was observed between the accessions belonging to different clusters. Since, high or optimum genetic divergence is desired between the parents of hybridization plan for obtaining higher frequency of desirable recombinants, the chances of obtaining good segregants by crossing the little diverse accessions belonging same cluster are very low. In order to increase the possibility of isolating good segregants in the segregating generations it would be logical to attempt crosses between the diverse accessions belonging to clusters separated by large inter-cluster distances. In present investigation maximum intra-cluster distance was observed for cluster VII (145.68), followed by cluster V (98.67), cluster VI (80.89), cluster II (72.04)) and cluster IV (70.52). However highest inter cluster distances were recorded between cluster $\mathrm{V}$ and VII (724.16) followed by cluster IV and VI (701.10), cluster IV and cluster VII (650.29) and cluster III and VII (613.61). The lowest inter cluster distance was observed between cluster I and III (90.95), followed by cluster I and II (115.37), cluster III and $\mathrm{V}(133.00)$, cluster I and IV (135.85) and cluster II and III (138.02). Thus, crossing between the accessions of the above cluster pairs having very low inter-cluster distances may not be rewarding owing to little genetic diversity among their accessions (Mehandi et al., 2015).

The intra-cluster group means for eight characters (Table 3) revealed marked differences between the clusters in respects of cluster means for different characters. Cluster II having 3 accessions, showed highest cluster means for number of seeds per pod and seed yield per plant second highest cluster means for plant height, primary branches per plant and pod length. Cluster III comprising 7 accessions, exhibited highest cluster mean for primary branches per plant and second highest cluster mean for days to maturity. Cluster IV having 6 accessions recorded lowest cluster mean for days to $50 \%$ flowering, plant height, number of seeds per pod, 100 seed weight and days to maturity. The 9 accessions of cluster $\mathrm{V}$ were responsible for highest cluster mean for days to $50 \%$ flowering, days to maturity and plant height. 
Table.1 Distribution of pigeonpea accessions into different clusters

\begin{tabular}{|c|c|c|}
\hline Clusters & $\begin{array}{c}\text { No. of } \\
\text { germplasm }\end{array}$ & Name of germplasm \\
\hline I & 17 & $\begin{array}{l}\text { Arhar Alsi, Desi Arhar Begari, PT- 0012, Mota Arhar Kartika, Pahadi Arhar, } \\
\text { Jamunia Rahri, Chotabali Arhar, Kumkum, AKT-8811, NTR-17, Bhura } \\
\text { Rahri, Marithi, Arhar Ganpad, Singhchaura Arhar, LRG-41, BSMR- } 853 \text { and } \\
\text { Local Arhar. }\end{array}$ \\
\hline II & 3 & Palki Arhar, Arhar Suryakant and HJPA-12. \\
\hline III & 7 & $\begin{array}{l}\text { Bumba Tumur, BDN-2, Chaita Arhar, BSMR-736, Karanja Tuar, Dehati } \\
\text { Arhar Lal and Belianga. }\end{array}$ \\
\hline IV & 6 & UPAS- 120, Paras, Manak, Dehati Arhar-2, Pusa-992 and Vamban-1 \\
\hline $\mathbf{V}$ & 9 & $\begin{array}{l}\text { Pili Arhar, Aasha, Chaitari Arhar, HJPA-16, Dhoba Arhar, Arhar Chaiti- P, } \\
\text { Arhar Desi- P, Desi Arhar- D and Lali Rahir. }\end{array}$ \\
\hline VI & 5 & Ram Arhar, HJP-7, Agahani, Manika Arhar and HJP-9. \\
\hline VII & 5 & NTH-77, Lal Rahri, Desi Arhar-1, Arhar Manpur Pahadi and Rehhe Arhar. \\
\hline VIII & 5 & Bar Garomah, Arhar-2, HJPA-21, HJPA-15 and NTH-11 \\
\hline
\end{tabular}

Table.2 Intra (diagonal) and inter cluster distances for different quantitative characters in pigeonpea

\begin{tabular}{|c|c|c|c|c|c|c|c|c|}
\hline Clusters & I & II & III & IV & V & VI & VII & VIII \\
\hline I & $\mathbf{5 1 . 8 9}$ & 115.37 & 90.95 & 135.85 & 213.00 & 462.15 & 564.43 & 263.56 \\
\hline II & & $\mathbf{7 2 . 0 4}$ & 138.02 & 232.04 & 197.35 & 357.47 & 442.07 & 201.62 \\
\hline III & & & $\mathbf{4 9 . 8 5}$ & 252.13 & 133.00 & 422.34 & 613.61 & 294.54 \\
\hline IV & & & & $\mathbf{7 0 . 5 2}$ & 474.33 & 701.10 & 650.29 & 340.57 \\
\hline V & & & & & $\mathbf{9 8 . 6 7}$ & 488.69 & 724.16 & 438.73 \\
\hline VI & & & & & & $\mathbf{8 0 . 8 9}$ & 202.30 & 157.53 \\
\hline VII & & & & & & & $\mathbf{1 4 5 . 6 8}$ & 153.69 \\
\hline VIII & & & & & & & & $\mathbf{4 8 . 3 3}$ \\
\hline
\end{tabular}

Table.3 Cluster means for different quantitative characters in pigeonpea

\begin{tabular}{|c|c|c|c|c|c|c|c|c|}
\hline Clusters & $\begin{array}{c}\text { Days to } \\
\text { 50\% } \\
\text { flowering }\end{array}$ & $\begin{array}{c}\text { Plant } \\
\text { height } \\
\text { (cm) }\end{array}$ & $\begin{array}{c}\text { Primary } \\
\text { branches/ } \\
\text { plant }\end{array}$ & $\begin{array}{c}\text { Pod } \\
\text { length } \\
\text { (cm) }\end{array}$ & $\begin{array}{c}\text { Number } \\
\text { of } \\
\text { seeds/ } \\
\text { pods }\end{array}$ & $\begin{array}{c}\text { 100 seed } \\
\text { weight } \\
\text { (g) }\end{array}$ & $\begin{array}{c}\text { Seed } \\
\text { yield/ } \\
\text { plant }\end{array}$ & $\begin{array}{c}\text { Days to } \\
\text { Maturity }\end{array}$ \\
\hline I & 118.57 & 150.49 & 11.02 & 5.40 & 3.79 & 10.09 & 28.29 & 185.41 \\
\hline II & 107.33 & 178.22 & 13.00 & 5.88 & 4.36 & 11.61 & 41.05 & 182.89 \\
\hline III & 128.19 & 148.52 & 13.91 & 5.29 & 3.76 & 10.43 & 31.84 & 220.86 \\
\hline IV & 91.06 & 135.50 & 12.17 & 4.94 & 3.10 & 9.60 & 30.14 & 156.72 \\
\hline V & 137.22 & 187.33 & 12.33 & 5.19 & 3.65 & 10.28 & 30.11 & 226.89 \\
\hline VI & 134.13 & 166.87 & 11.47 & 6.14 & 4.33 & 18.38 & 29.03 & 217.20 \\
\hline VII & 107.40 & 173.47 & 12.13 & 4.91 & 3.40 & 19.36 & 28.16 & 174.53 \\
\hline VIII & 110.33 & 154.47 & 10.07 & 5.10 & 3.59 & 16.39 & 37.88 & 187.87 \\
\hline
\end{tabular}


Table.4 Percent contribution of different quantitative characters towards genetic divergence in pigeonpea

\begin{tabular}{|l|l|c|}
\hline S. No. & Source & Contribution towards divergence (\%) \\
\hline $\mathbf{1}$ & Days to 50\% Flowering & 10.59 \\
\hline $\mathbf{2}$ & Plant Height $(\mathrm{cm})$ & 12.72 \\
\hline $\mathbf{3}$ & Primary Branches/ Plant & 1.25 \\
\hline $\mathbf{4}$ & Pod Length $(\mathrm{cm})$ & 3.07 \\
\hline $\mathbf{5}$ & Seeds/ Pod & 2.57 \\
\hline $\mathbf{6}$ & 100 Seeds Weight $(\mathrm{g})$ & 49.37 \\
\hline $\mathbf{7}$ & Yield/ Plant (g) & 1.75 \\
\hline $\mathbf{8}$ & Days to Maturity & 18.67 \\
\hline
\end{tabular}

Fig.1 Grouping pattern (Euclidean method) of pigeonpea genotypes

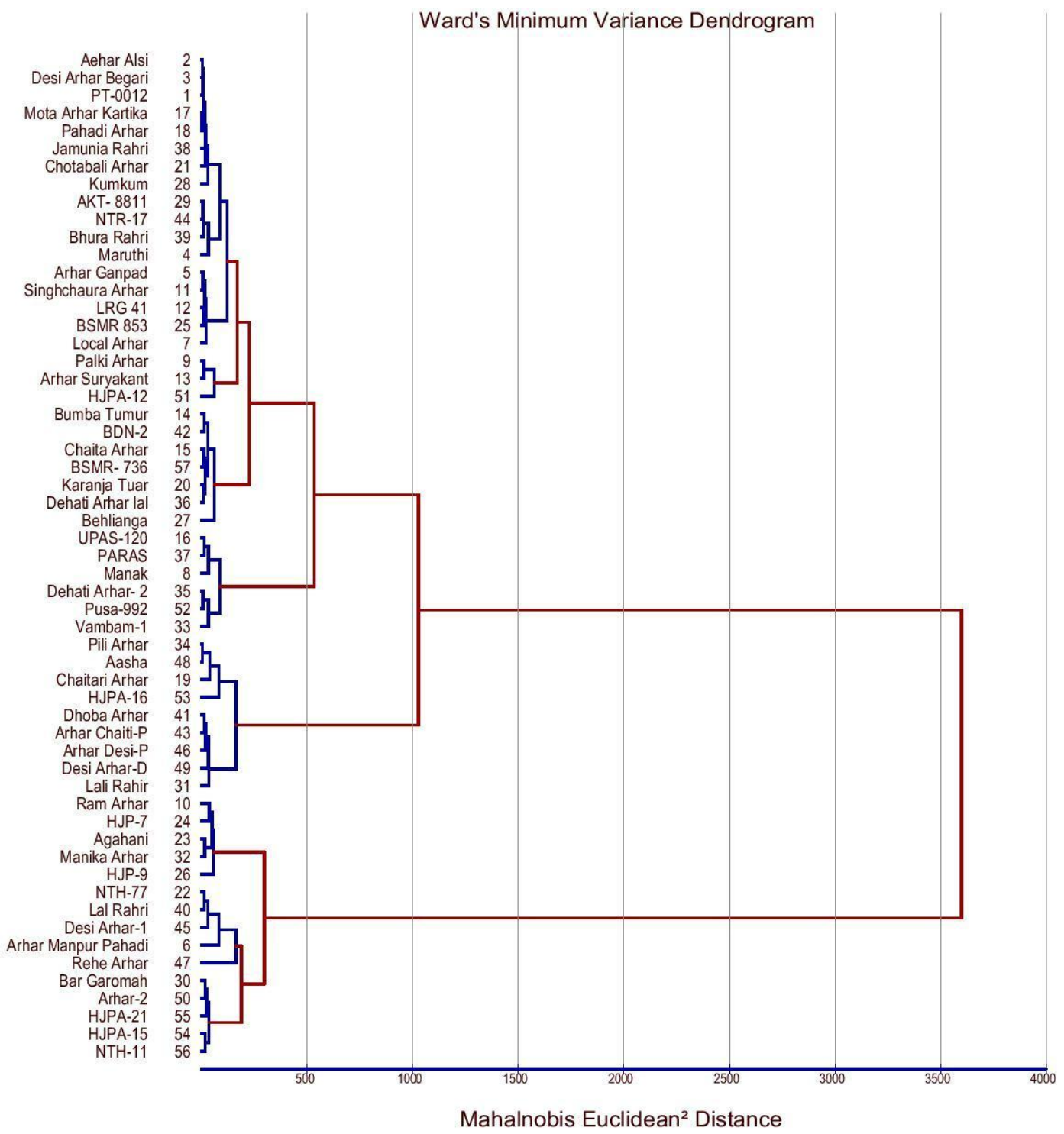


Fig.2 Cluster diagram showing Euclidean ${ }^{2}$ distance

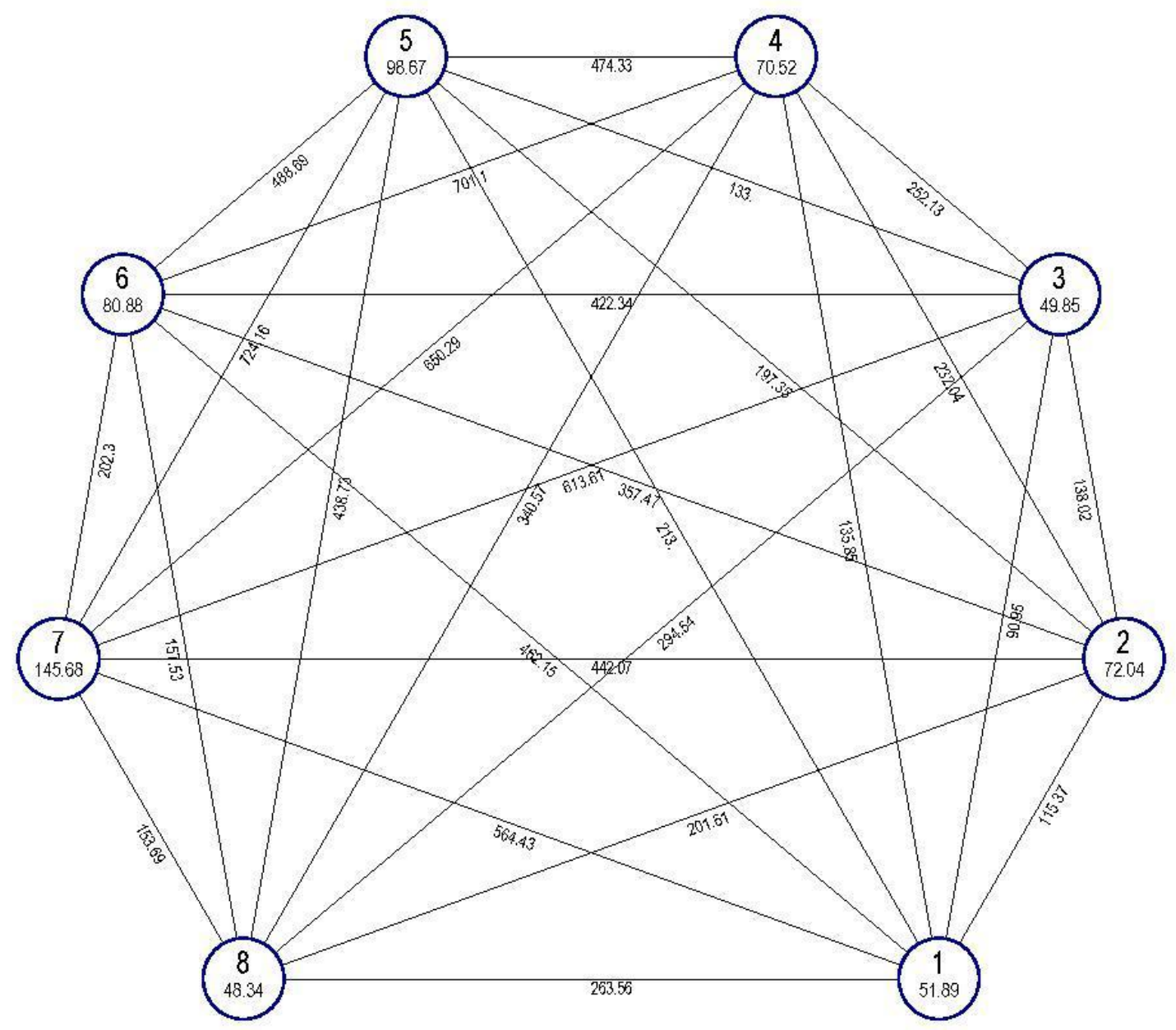

Euclidean ${ }^{2}$ Distance (Not to the Scale)

Cluster VI possessing 5 accessions, has highest means for pod length and second highest cluster means for days to $50 \%$ flowering, number of seeds per pod and 100 seed weight. Cluster VII having 5 accessions showed highest cluster mean for 100 seed weight besides having lowest cluster means for pod length and seed yield per plant. Cluster VII comprising 5 accessions exhibited second highest cluster mean for seed yield per plant besides having lowest cluster means for primary branches per plant Similar findings were also reported by (Sawant et at., 2009 and Pratap et al., 2011).

Efficiency of $\mathrm{D}^{2}$ statistics is improved by its applicability to estimate the relative contribution of the various characters towards genetic divergence (De et al., 1992; Mehandi et al., 2018). In this context, the highest contribution in manifestation of genetic divergence was exhibited by 100 -seed weight followed by days to maturity, plant height and days to $50 \%$ flowering (Table 4 ). 
The hybridization between the entries belonging to cluster pairs having large intercluster distance and possessing high cluster means for one or other characters to be improved may be recommended for isolating desirable recombinants in the segregating generations in pigeonpea. The promising accessions identified were Bumba Tumur, BDN-2, Chaita Arhar, BSMR-736, Karanja Tuar, Dehati Arhar Lal and Belianga of cluster III; UPAS- 120, Paras, Manak, Dehati Arhar-2, Pusa-992 and Vamban-1 of cluster IV, Ram Arhar, HJP-7, Agahani, Manika Arhar and HJP-9 of cluster VI and NTH-77, Lal Rahri, Desi Arhar-1, Arhar Manpur Pahadi and Rehhe Arhar of cluster VII for exploitation in hybridization programme for development of superior pigeonpea cultivars. However, caution should be exercised in selecting very diverse accessions, because the frequency of heterotic crosses and magnitude of heterosis for yield and its components were found to be higher in hybridization between parents with intermediate divergence than the extreme ones.

\section{Acknowledgement}

The authors are highly thankful to the Honble Director ICAR-Indian Institute of Pulses Research, Kanpur for providing all the necessary facilities to conducting the experiment.

\section{References}

Arunachalam, V. 1981. Genetic distance in plant breeding," Indian Journal of Genetics and Plant Breeding, 41(2): 226-236.

Bhadru, D. 2011. Genetic studies in pigeonpea [Cajanus cajan (L.) Millsp]," Electronic Journal of Plant Breeding, 1(2): 132-134.

Bhatt, G.M. 1970. Multivariate analysis approach to selection of parents for hybridization aiming at yield improvement in self-pollinated crops. Australian Journal of Agricultural Research (2): 1-7.

Darwin, C. 1859. The origin of species by means of natural selection or the preservation of favored races in the struggle for life. Philosophical Library, New York

De, R.N., Reddy, J.N., Rao, A.V.S. and Mohanty, K.K. 1992. Genetic Divergence in Early Rice under Two Situation," Indian Journal of Genetics and Plant Breeding, 52(3): 225-229.

Gupta, S.K., Sandhu, J.S., Singh, S. and Dua, R.P. 2008. Assessment of genetic diversity in pigeonpea [Cajanus cajan (L.) Millsp.], Crop Improvement, 35(2):142-145.

Katiyar, P.K., Dua, R.P., Singh, I.P., Singh, B.B. and Singh, F. 2004. Multivariate analysis for genetic diversity in early pigeonpea accessions," Legume Research, 27(3):164-170

Mahalanobis, P.C. 1936. On the generalized distance in statistics. Proceedings of National Institute of Sciences 2: 49-55.

Mehandi S, Singh IP, Bohra A, Singh CM 2013 (Supplement on Genetics \& Plant Breeding) Estimates of genetic variability and heritability for yield and yield component traits in mungbean [Vigna radiata (L.) Wilczek] The Bioscan, 8(4): 00-00

Mehandi S, Singh IP, Bohra A Singh CM 2015. Multivariate analysis in green gram [Vigna radiata (L.) Wilczek], Legume Research 38(6): 758-762.

Mehandi S, Mishra SP, Tripathi RC, and Singh IP 2018. Genetic variability, heritability and genetic advance for yield and its related traits in mungbean [Vigna radiata (L.) Wilczek] genotypes. International Journal of Current Microbiology and Applied Sciences, Special Issue-7: 3818-3824. 
Moll, R.N., Sathawana, W.S., and Robinson, H.F. 1962. Heterosis and genetic diversity in varietal crosses of maize. Crop Science 2:197-198.

Murty, B.R. and Arunachalam, V. 1966. The nature of genetic divergence in relation to breeding system in crop plants. Indian Journal of Genetics and Plant Breeding, 26:188-198.

Nag, Y.K. and Sharma, R.N. 2012. Genetic diversity and path coefficient analysis in pigeonpea [Cajanus cajan (L.) Millsp.] germplasm accessions of Bastar origin," Electronic Journal of Plant Breeding, 3(2): 818-824

Panse, V.G. and Shukhatme, P.V. (1967). Statistical methods for agricultural workers, 2nd edition, Delhi. Pp. 152157.

Pratap, N., Kumar, R., Singh, S.N., Singh,
R.J. and Verma, H.R. 2011. Genetic divergence in pigeonpea collections, Agricultural and Biological Research, 27(1): 14-19.

Rao, C.R. (1952) Advanced statistical methods in biometric research," John Wiley and Sons, New York.

Sawant, M.N., Sonone A.H. and Anarase, S.A. 2009. Character association, path coefficient analysis and genetic diversity in pigeonpea, Journal of Maharashtra Agricultural Universities, 34(2):134-137.

Singh CM, Mishra SB, Pandey A, Arya M 2014a. Morphological characterization and discriminant function analysis in mungbean. Electronic Journal of Plant Breeding. 5:87-96.

\section{How to cite this article:}

Syed Mohd Qutadah, Suhel Mehandi, I.P. Singh and Farindra Singh. 2019. Assessment of Genetic Diversity for Polygenic Traits in Pigeonpea [Cajanus cajan (L.) Millspaugh]. Int.J.Curr.Microbiol.App.Sci. 8(01): 1581-1588. doi: https://doi.org/10.20546/ijcmas.2019.801.166 